\title{
MODELOS COGNITIVOS DE ENSINO E PRÁTICAS PEDAGÓGICAS - PLANIFICAÇÃO DE UMA AULA DE HISTÓRIA SEGUNDO O MODELO RESOLUÇÃO DE PROBLEMAS ${ }^{1}$
}

Odília Maria Gontardo Freitas Castro Leal ${ }^{2}$

Resumo: Com este trabalho pretendo aprofundar a compreensão do paradigma cognitivo, a partir da sua relação com um dos modelos nele inspirado, o modelo Resolução de Problemas, aplicado a uma aula de História. Na primeira parte, começarei por clarificar os conceitos de pressuposto, paradigma e modelo, evidenciando a sua relação dialéctica. Seguidamente, procederei à caracterização do paradigma cognitivo, referindo os suportes em que assenta, as linhas estruturantes e os seus aspectos caracterizadores. Após uma abordagem dos modelos cognitivos de ensino, onde farei referência aos suportes conceptuais que caracterizam as suas principais práticas, destacarei o modelo Resolução de Problemas e descreverei a sua sintaxe. Numa segunda parte, irei enfrentar o desafio de aplicar o modelo em causa, a um cenário de uma aula de História do Ensino Secundário, em torno de um problema ligado à História Local.

Palavras-chave: Modelos de Ensino. Modelos Cognitivos. Modelo Resolução de Problemas. 


\section{INTRODUÇÃO}

Ultrapassada a dicotomia educação/instrução e uma vez assumida a ideia da perfectibilidade e do inacabado, torna-se imperioso admitir que o ser humano, desde o seu nascimento até a sua morte, está sempre a aprender. Só aprendemos em interacção com os outros. Ensinar e aprender são actos complementares, embora, como diz a Professora Ivone Gaspar, o ensinante e o aprendente desempenhem, obviamente, papéis «que podem não resultar numa relação directamente proporcional $»^{3}$

Ensinar pressupõe uma intencionalidade e é um acto que não pode aparecer dissociado do sujeito a quem se espera que a aprendizagem ocorra. Não podemos dizer que ensinamos alguém, sem que esse alguém tenha aprendido e, por isso, é cada vez mais consensual a ideia de uma boa base teórica, em que os modelos de ensino e aprendizagem constituem um ponto de partida.

Ao longo dos tempos, têm sido criados vários modelos de ensino e aprendizagem, os quais se apoiam em paradigmas que são sustentados por pressupostos de naturezas várias. Porém, os modelos não são contraditórios e não se excluem mutuamente, e o mais importante é saber adequar-se a cada situação concreta e a cada contexto, até porque cada indivíduo constrói os seus próprios significados, mediante as interacções que lhe são proporcionadas. Neste sentido, o ensino deixa de ser encarado como o relato ou a transmissão de verdades e o professor passa a ser um moderador, um facilitador, um construtor de ambientes de aprendizagem propícios ao desenvolvimento de capacidades abertas, da aquisição de instrumentos que permitam adquirir a própria aptidão para continuar a aprender. Aprender é proceder a uma síntese infinitamente renovada entre a continuidade e a novidade. A escolarização é apenas uma etapa no longo e dinâmico processo de educação e, por isso, deve ancorar-se na resolução de problemas, no desenvolvimento de competências e na preparação dos indivíduos para a inserção na vida activa, onde cada um possa realizar-se plenamente em interacção com os outros, contribuindo para a concretização de projectos comunitários em que todos ensinam, aprendem, educam e são educadores (Delors, 2005). 


\section{OS CONCEITOS: PRESSUPOSTO, PARADIGMA E MODELO}

Partimos do princípio que ensinar com eficácia não é apenas uma arte ou um dom, exigindo a aquisição de métodos e técnicas sustentadas em modelos de ensino e aprendizagem. Estes apoiam-se em paradigmas, os quais, por sua vez, alicerçam-se, em pressupostos, em linhas orientadoras que funcionam como as bases para as comunidades se organizarem. Os principais pressupostos são de carácter filosófico, psicológico, sociológico e pedagógico.

Os pressupostos filosóficos abordam o conceito de homem e a sua essência e estão na base de todos os outros. Qualquer acto pedagógico está, implícita ou explicitamente, ligado à Filosofia. Ao longo dos tempos, salientam-se quatro pontos essenciais: a matriz racionalista que, partindo da ideia da crença ilimitada na razão e no progresso, colocou a tónica na liberdade individual e no dever do adulto e do Estado educarem a criança; o existencialismo e a corrente hermenêutica que vieram valorizar os ideais pessoais e únicos de cada um, tornando-nos responsáveis pelo destino próprio; o estruturalismo que, entre outros aspectos, propõe a explicação das acções individuais através do inconsciente e de forças histórico-sociais e o pragmatismo que coloca a ênfase nas consequências e proclama o conhecimento e a aprendizagem como construções sociais. ${ }^{4}$

Os pressupostos psicológicos têm também uma importância fundamental, pois evidenciam aspectos importantes como a inteligência, a personalidade e a motivação, o que se torna essencial para compreender a criança e o seu modo de aprender. Piaget (1896-1980), Skinner (1974), Bruner (1977), Vigotsky (1985) trouxeram contributos fundamentais ao ensino e as suas teorias sustentam paradigmas, modelos e teorias que, apesar das diferenças, acabam por se completarem.

Os pressupostos sociológicos prendem-se com o fenómeno da socialização, primária e secundária, e ajudam a fundamentar uma visão da escola como meio de potenciar a igualdade, mostrando que o peso do meio social pode ser alterado através de estratégias que contrariem os condicionamentos relacionados com a origem, o que confere aos educadores um papel decisivo. 
Os pressupostos pedagógicos são aqueles onde todos os outros confluem. O contributo das ideias acima referidas foi muito importante para uma nova visão da pedagogia, tendendo cada vez mais para a valorização do desenvolvimento harmonioso e completo do ser humano, onde a dimensão afectiva e social é tão importante como a estritamente cognitiva e onde o erro (desde que não seja sistematicamente repetido ${ }^{5}$ é visto como fonte de conhecimento e o trabalho cooperativo e colaborativo tidos como fundamentais.

Todos estes pressupostos apoiam os vários paradigmas que suportam o ensino e a aprendizagem, embora num jogo de interacções variadas e complexas.

OA palavra paradigma é relativamente recente e remete para um conjunto de valores e crenças partilhadas por uma sociedade, de modo a que essa seja organizada. Como qualquer conceito recente, não há consensualidade quanto a sua articulação com o real; apesar de haver um paradigma dominante, ele convive sempre com elementos da sua própria negação - os contra-paradigmas - até porque estão em jogo os mesmos pressupostos, embora articulados de modo diverso e com enfoques distintos. Um paradigma é um «quadro de referência norteador da acção» 6 .

Os paradigmas mais importantes e que hoje inspiram os principais modelos de ensino e aprendizagem são: o paradigma cognitivo (que será destacado neste ensaio), o paradigma comportamental (que afasta a ideia do determinismo biológico e da hereditariedade intelectual e centra-se na importância da resposta do aprendente a estímulos de natureza física ou simbólica, tendo Thorndike - 1874/1949 - e Skinner - 1904/1990 - como seus principais entusiastas) e o paradigma interpessoal (onde confluem essencialmente contributos da sociologia e da psicologia, destacando-se nomes como Dewey (1916), Thelen (1981) e Kagan 19997; a escola é vista como um microcosmos da sociedade, colocando-se a tónica no carácter relacional dos seres humanos e apelando-se ao ensino cooperativo e colaborativo).

Assim, os paradigmas alimentam constelações de modelos educacionais de ensino-aprendizagem, os quais, concordando com Yves Bertrand ${ }^{8}$, podem ser definidos como «as regras e valores que devem presidir à planificação da educação e à organização das actividades pedagógicas», o que pressupõe «um lado prático e prescribente mais evidente» do que na noção de 
paradigma e, por sua vez implica uma imensa variedade de métodos, técnicas e estratégias ${ }^{9}$ que, embora inspiradas em cada modelo, podem complementar-se e ser usadas em simultâneo.

Segundo a Professora Ivone $\operatorname{Gaspar}^{10}$, a palavra modelo comporta uma «carga sociológica e psicológica que denota alguma negatividade quanto à interpretação e respectiva aplicação», impondo-se «cada vez mais, como um padrão referencial não no singular mas numa pluralidade enriquecida pela diferença» e podemos comparar as famílias de modelos «a uma avenida, donde saem várias ruas que se vão intersectando». Os modelos exercem um papel chave e têm «poder» sobre todo o tipo de alunos e alargam a área do «campo de jogo» do professor, porque ensinam a qualquer aluno como aprender e possuem a «flexibilidade adaptativa para acomodar produtivamente as diferenças e rentabilizá-las», tornando o ensino maleável.

Antes de se passar à caracterização mais pormenorizada do paradigma em análise (o cognitivo), convém referir que, apesar da pluralidade de modelos, os quais se interligam com várias metodologias ${ }^{11}$, normalmente estabelece-se a seguinte relação: o paradigma cognitivo gera essencialmente dois modelos: o modelo da aprendizagem de conceitos e o da resolução de problemas; o paradigma comportamental conduz ao modelo da mestria e ao da instrução directa e o modelo interpessoal promove, sobretudo, o modelo da investigação em grupo e o de questionamento jurisprudencial.

Porém, nunca é demais sublinhar que não há modelos universalmente válidos e a sua aplicabilidade e validade é sempre condicional, havendo múltiplos modelos alternativos, a possibilidade de combinações e explorações transversais e até a hipótese, sempre em aberto, de cada professor, numa postura que se quer sempre reflexiva e investigativa, contribuir para a criação de novos modelos, pois alunos diferentes podem atingir os mesmos objectivos segundo processos diferentes.

\section{O PARADIGMA COGNITIVO}

No paradigma cognitivo privilegia-se o estudo dos processos cognitivos, e o conceito de representação (interna ou externa) é considerado crucial, ainda que esteja sujeito a diferentes interpretações. Na verdade, os conceitos são representados mentalmente e usados pelas pessoas para se 
relacionarem com o mundo. À luz deste paradigma, o conhecimento nãoé inato, é pessoal e socialmente construído sem a pretensão de atingir a verdade indiscutível acerca do mundo. «O conhecimento de cada ser humano é uma construção pessoal e ideossincrática de significados acerca dos objectos/conhecimentos, os quais vão evoluindo de acordo com a experiência de vida ${ }^{12}$.

\subsection{PRESSUPOSTOS EM QUE ASSENTA O PARADIGMA COGNITIVO}

Pensamos que as raízes profundas do paradigma cognitivo podem ser encontradas na Antiguidade Clássica. $\mathrm{O}$ mito da caverna mostra que é possível o alargamento do conhecimento, o caminho para a verdade e cabe ao educador um papel importante, ajudando o sujeito a sair do mundo das sombras para a conquista das luzes.

Mas será Rousseau, no século XVIII, o grande impulsionador do princípio da educabilidade, base dos processos cognitivos. Como seres inacabados, estamos sempre em construção e aperfeiçoamento, o que supõe que se espere sempre o sucesso do outro e que se faça tudo para que tal aconteça. Como o desenvolvimento pessoal não se realiza fora do círculo social, não há margem para visões individualistas.

Os fundamentos psicológicos desse paradigma encontram-se no construtivismo piagetiano, o qual se centra no desenvolvimento do pensamento lógico da criança. Piaget (1896-1980) não se ocupou dos problemas afectivos, apesar de lhes reconhecer importância; preocupouse com o conhecimento e estudou o sujeito como construtor activo de conhecimento. O facto mais importante é o desenvolvimento dessa construção do saber, onde a acção tem um papel determinante, mas não se trata de uma acção reduzida à motricidade. É um acto muito mais complexo que encontra a sua pertinência na operação, cujas propriedades são a interiorização (capacidade de pensar a acção), a reversibilidade (possibilidade de fazer a acção e depois de a desfazer) e a articulação de diversas operações num agrupamento: a estrutura. As funções cognitivas estabelecem-se, inicialmente, no plano concreto, de forma essencialmente motora e intuitiva, depois, pouco a pouco, desenvolvem-se no plano formal 
e articulam-se em estruturas.

Podemos afirmar que o principal resultado do pensamento piagetiano para o ensino tem a ver com o novo olhar sobre a aprendizagem, encarada como um processo onde o aprendente interage com o meio e não mais deve ser encarado com um ser passivo.

Na sequência destas constatações, Jerome Bruner (1915) debruçouse essencialmente sobre o desenvolvimento de conceitos. A sua teoria de desenvolvimento conceptual é uma das primeiras perspectivas teóricas sobre como as capacidades cognitivas se revelam nas tarefas de ensino e acredita que a abordagem ao conhecimento se faz propondo problemas, partindo do que o aluno sabe e que todas as crianças podem aprender qualquer assunto, em qualquer idade, desde que se use estratégias adequadas. Este autor valorizou particularmente as motivações intrínsecas como recompensadoras e auto-suficientes, o que se traduz num auxiliar precioso em situação de aula, por exemplo, na exploração de alternativas na resolução de problemas, onde uma dose equilibrada de incerteza pode activar o interesse, aspecto que foi aprofundado por Hunter (1971).

Estas e outras teorias cognitivas suportam o paradigma cognitivo, permitindo a identificação de duas linhas de investigação com consequências ao nível do processo de ensino e de aprendizagem: a que fundamenta uma pedagogia da compreensão e a que sustenta principalmente a procura da eficácia de resultados.

As linhas estruturantes dum paradigma polarizam-se em torno do seu objecto de estudo, da ideia que o originou, da sua orientação e da sua expectância (Gaspar et al., 2008)

No que diz respeito ao objecto de estudo, o cognitivismo perspectivase como um conhecimento de natureza multidisciplinar, cujo objectivo é o de estudar a mente humana, a inteligência, o pensamento. Esta natureza confere, assim, às ciências cognitivas um carácter transversal. A análise dos processos cognitivos, passa pela investigação sobre os modos como a mente humana funciona. Entre esses processos, encontram-se a memória, a percepção e o raciocínio.

Na ideia que originou o paradigma cognitivo, está a influência de Bruner (1915), em particular no que diz respeito às tentativas para se estabelecer o significado como conceito central da psicologia. O paradigma que então se assumia como fundamental era o comportamentalista e quando a 
corrente cognitivista começou a ganhar forma, a ideia não era a de se antagonizar as duas abordagens. Mas a corrente cognitivista acabou por evoluir mais rapidamente que o esperado, com a evolução do "significado" para a "informação" e da "construção de significado" para o "processamento da informação".

Relativamente à orientação do paradigma cognitivo, dá-se importância à informação, para a qual não interessa o significado, já que o processamento de informação exige regras muito precisas e planificação prévia. Com Vygotsky (1896-1934), autor que lança as bases do Interaccionismo ${ }^{14}$, surgiu uma perspectiva diferente, passando-se da explicação sobre a cognição, como um processo localizado no sujeito, para a compreensão do contexto interpessoal do crescimento cognitivo, por se considerar que os factores contextuais são vistos como moderadores do crescimento cognitivo. Este conceito de cognição evoluiu para o de "cognição situada", face à valorização da interacção social nos processos cognitivos.

Sobre a expectância pode afirmar-se que a evolução é no sentido de se explicar a natureza da aprendizagem e dos processos de pensamento, com recurso à psicologia cognitiva, o que se traduz na crença de que só depois de se conhecer mais sobre os processos mentais e sobre as mudanças operadas na competência, é possível desenvolver teorias sobre como organizar as tarefas de modo a que todos aprendam eficazmente

Assim, este paradigma pode ser caracterizado ${ }^{14}$ pelos seguintes aspectos: a) O sujeito constrói o conhecimento em interacção com o meio; o ser humano é um ser cognitivo e o conhecimento depende de construções sucessivas com a formação de estruturas novas; b) Ao construírem conhecimento, os sujeitos esforçam-se por ser eficazes e atribuir significado às suas experiências e a nova informação não é apenas uma soma de outras informações; c) O conhecimento é sempre, ainda que parcialmente, «reinventado» por cada sujeito; d) Cada aprendente compreende os conceitos de modo diferente; e) As principais preocupações centram-se nos processos cognitivos, valorizando aspectos como o raciocínio, a resolução de problemas, as representações e as imagens mentais; f) $\mathrm{O}$ acto de representação é fundamental e por isso o significado da experiência é sempre representado através de símbolos, palavras ou modelos; g) Os sistemas de representação, utilizados no pensamento e na comunicação têm um papel estruturante na formação de conceitos; h) Apesar de não 
ignorar os aspectos afectivos, atitudinais e socioculturais, não os valoriza suficientemente.

Como se depreende dos contributos atrás referidos, este paradigma já não se reduz à visão estritamente piagetiana, assumindo uma dimensão mais abrangente, onde ao domínio cognitivo se junta o domínio conativo, definido por Reuchlin ${ }^{15}$ como «o que diz respeito à motivação, à afectividade, às emoções, ao temperamento, à personalidade ... ao controlo e à regulação das condutas».

\section{MODELOS COGNITIVOS DE ENSINO}

Na sequência do que foi dito sobre o conceito de modelo, convém sublinhar que não há receitas nem remédios milagrosos, cabendo ao educador a competência para convocar os melhores métodos e as melhores estratégias decorrentes do modelo mais adequado a cada situação concreta, consoante os tipos de aprendentes, os contextos e os objectivos pretendidos.

Os modelos cognitivos permitem utilizar metodologias que constituem uma alternativa ao ensino de tipo acumulativo, mecânico, sequencial e linear, facilitando uma aprendizagem mais global, significativa e duradoura, em que o novo se ancora em conceitos e proposições previamente existentes na estrutura cognitiva. Podemos afirmar que todos estimulam práticas que possuem os seguintes elementos conceptuais comuns ${ }^{16}$ : a) Aderem ao princípio da perfectibilidade que, consoante os autores, é designado por educabilidade, modificabilidade, prognóstico de progressão ou reinício; b) Interpretam o erro, não como uma falta, mas como revelador de um processo autêntico do pensamento em evolução; c) Consideram que o professor desempenha sobretudo um papel de facilitador, de mediador entre o saber e o aluno; d) Pretendem, na sua grande maioria, favorecer a consciencialização por parte do aluno do seu próprio funcionamento cognitivo; e) Postulam que o saber não é cristalizado, mas evolui: não resulta de reprodução, mas de construção; f) Dão uma resposta particularmente pertinente às disfunções da estruturação operatória, dando ao professor um papel de mediador que consiste em ajudar o aluno a construir o raciocínio lógico; g) Validam a prática do trabalho 
em grupo, o que permite experimentar intercâmbios enriquecedores e com alto grau de interactividade; h) Permitem não voltar a confundir competência com desempenho, pois o professor compreende que o potencial susceptível de evolução já não se restringe a uma imagem somativa e o aluno toma consciência do seu potencial e das estratégias de que dispõe para as fazer emergir.

Segundo a Professora Ivone Gaspar ${ }^{17}$, os modelos da «Família» cognitiva partilham três axiomas acerca da inteligência que contrariam os que a sociedade, em geral, ainda assume: a) sexo, raça e etnicidade não afectam o desenvolvimento da inteligência; b) a inteligência não é fixa, pode ser alterada e ensinada; c) a inteligência é multidimensional; algumas das suas dimensões podem ser rentabilizadas através de modelos específicos de aprendizagem e/ou ensinadas através deles e são úteis para atingir objectivos de natureza pessoal e social.

De entre uma gama variada de modelos cognitivos, destacam-se o modelo Aprendizagem de Conceitos, aprofundado por Jerome Bruner ${ }^{18}$ e o modelo Resolução de Problemas, que abordarei seguidamente.

\subsection{MODELOS COGNITIVOS DE ENSINO}

O modelo Resolução de Problemas tem por base a investigação realizada no âmbito da psicologia cognitiva sobre a resolução de problemas, o que implica encontrar uma sequência de operadores para transformar um estado inicial num outro estado que se pretende alcançar.

Dois conceitos fundamentais enformam este modelo: as heurísticas (actividades que orientam a aprendizagem, mas não garantem necessariamente o sucesso) e os algoritmos (as actividades que, se bem orientadas, conduzem à resolução do problema).

Durante a resolução dos problemas os alunos devem ter disponíveis heurísticas que os ajudem a tomar decisões e a desdobrar os problemas em sub-problemas, analisar criticamente as informações, simular situações possíveis, organizar os dados e formular problemas pelas suas próprias palavras. Também é muito utilizada a resolução por analogia, ou seja, utilizando estruturas de outras situações problemáticas, mas em novos contextos. 
Este modelo implica que o professor prepare materiais e crie situações onde os alunos possam seleccionar problemas que exijam o domínio de conhecimentos específicos, transferindo-os de outros contextos e disponibilizem um conjunto de heurísticas no delineamento das actividades de resolução. Costuma-se distinguir dois tipos de conhecimento: o declarativo (factos e regras) e o procedimental (como realizar as actividades).

O que verdadeiramente define um modelo de ensino é a sua sintaxe e este modelo normalmente desenvolve-se através de seis fases, durante as quais os alunos terão oportunidade de, através de tentativas e erros, escolher as melhores opções, iniciar e reiniciar, reinterpretar, pensar sobre a sua actuação e explicá-la, desenvolvendo competências de metacognição, sempre sob o olhar atento, mas discreto do professor. $\mathrm{O}$ papel do professor é de monitorizar, orientar, dar pistas, estar atento à evolução dos alunos, valorizando a vertente formativa da avaliação.

Eis uma descrição mais pormenorizada da sintaxe do modelo Resolução de Problemas ${ }^{19}$ :

\section{Fase 1: Reconhecimento do problema}

O professor apresenta o problema e convida os alunos a lerem o exto que sintetiza o problema; questiona os alunos na tentativa de dentificarem o que se pretende saber (ou obter) e a especificarem odos os dados explícitos no enunciado.

\section{Fase 2: Análise da situação problemática}

O professor, por meio de questões, orienta os alunos na identificação dos princípios/conceitos/ideias que estão implicados na situação onde se coloca o problema, procurando que eles possam ajuizar sobre o seu estado de conhecimentos quanto a essas ideias/conceitos/princípios.

Os alunos, ajudados pelo professor, tentam colmatar essas falhas e procuram, ainda, ver se há ou não dados implícitos que devem pesquisar e ter em conta e, se necessário, como fazer para obter esses dados.

Fase 3: Delineamento de estratégias de resolução

O professor procura incentivar os alunos a colocarem hipóteses sobre os passos a realizar para obter uma solução para o problema e a seleccionarem uma estratégia possível; para isso, se necessário, o professor dá pistas de possíveis percursos. 


\section{Fase 4: Concretização}

Os alunos procuram resolver o problema de acordo com a estratégia escolhida; o professor apoia os alunos se for solicitado para isso.

\section{Fase 5: Análise de processos e de resultados}

O professor incentiva os alunos, através de instruções explícitas фu usando questões, a apreciar se o que obtiveram se encontra dentro da gama de resultados com significado para a situação problemática de acordo com o enunciado originário; de acordo com essa análise os łlunos são convidados a reverem a estratégia usada e a procurar possíveis fontes de erro se a solução encontrada não é coerente com ф esperado e com o enunciado; se se verificar que a solução é coerente фs alunos são convidados a identificarem os passos e processos que usaram e que se revelaram mais importantes para encontrar a solução.

\section{PLANIFICAÇÃO DE UMA AULA DE HISTÓRIA SEGUNDO O MODELO RESOLUÇÃO DE PROBLEMAS}

O modelo Resolução de Problemas tende a ser associado às matemáticas e às ciências naturais e laboratoriais e é pouco vulgar a sua aplicação na nossa área de trabalho - a História. Este facto relaciona-se com um conceito positivista desta disciplina que tem imperado nas escolas, mas que, felizmente, começa a dar lugar a uma História assumidamente construída.

Será viável a utilização deste modelo em aulas de História? Em caso afirmativo, que conteúdos se prestarão melhor a serem tratados através deste modelo? Que mais-valias resultarão para os alunos da utilização deste modelo em aulas de História?

Após várias experiências, começamos a ganhar a convicção de que o modelo Resolução de Problemas pode constituir um auxiliar precioso para o tratamento dos temas de História Local, já que os seus conteúdos são facultativos e, portanto, da inteira responsabilidade de cada professor, obrigando a convocar competências e conhecimentos adquiridos noutros contextos, em situações diversas e temporalmente distintas. Por outro lado, o facto de os manuais não trazerem dados concretos sobre estas temáticas, implica que tenha que haver pesquisa por parte dos alunos, o que é estimulante para se 
iniciar um projecto a partir da colocação de um problema relacionado com a História do município onde se vive.

Uma vez cimentada a fundamentação da nossa opção, colocou-se a questão das técnicas, estratégias e métodos a privilegiar na implementação do modelo escolhido. Convém clarificar estes conceitos decorrentes da ideia de modelo e muitas vezes tratados como sinónimos, talvez por actuarem ao mesmo nível - o das práticas pedagógicas concretas.

O conceito de técnica, tem uma dimensão muito prática e visa a obtenção de resultados concretos, cruzando eventualmente vários modelos e funcionando já no campo de uma disciplina específica. De facto a Techne, como conjunto das técnicas, implica a utilização de materiais ligados aos procedimentos que visam coadjuvar o professor no seu trabalho, estando adstrita a formas de apresentação imediata de um conteúdo.

O termo estratégia, talvez por vir dos domínios militares, tem sido usado numa multiplicidade de contextos e com acepções muito diversas. Por vezes é usado como sinónimo de actividade, táctica e habilidade. Vários autores como Clarke e Biddle, Lamas e Nisbet e Shucksmith (citados por Perraudeau, 2000: 16) usam o conceito no sentido de plano de acção cuidadosamente preparado, envolvendo uma sequência de passos concebidos para atingir uma determinada meta. As estratégias podem ser classificadas em função de vários factores: a) O grau de envolvimento do professor (centradas no Professor ou no Aluno); b) Os modelos a que estão associadas (por exemplo, estratégias Indutivas ou Dedutivas); c) As situações da vida real (Inquérito, Estágios, Meditação, Estruturadores Gráficos, Questionamento); d) As simulações da realidade (Role-play, Dramatização, Brainstorming, Grupos de Discussão, Jogos); e) As abstracções da realidade (Exposição - Leitura, Escrita, Discurso, Exética, LeituraDemonstração, Recitação - Treino ou Prática e Exame ou Desafio).

Quanto ao método, é, segundo Azevedo e Azevedo ${ }^{20}$, «um conjunto de procedimentos que compõem um projecto», remetendo, neste caso, para uma visão globalizante e associando-se aos vários modelos decorrentes do mesmo paradigma. Nesta linha, falar-se-á em métodos cognitivos, métodos comportamentais e métodos interpessoais. 
Maryvonne Sorel ${ }^{21}$ alerta contra a armadilha de se querer aplicar um método uniforme que parta de um nível idêntico para todos os alunos. A autora define uma classificação dos métodos cognitivos em cinco grandes categorias: 1. Os que intervêm directamente nas competências cognitivas, nos quais existem três categorias: os métodos centrados nas operações mentais (por exemplo, os ARL - Ateliers de Raciocínio Lógico); os centrados na aprendizagem das condições do pensamento (por exemplo, o método Ramain) e os que se interessam pela estruturação cognitiva a partir de um suporte informático. 2. Os centrados nas competências formais e simbólicas, necessárias em situação de raciocínio ou de resolução de problemas (por exemplo, os cubos de Mialet). 3. Os métodos que visam a autonomia do aluno no seu processo de aprendizagem (por exemplo, a gestão mental). 4. Os que facilitam o conhecimento de si mesmo. 5. Os que se baseiam nas componentes fisiológicas do cérebro.

Independentemente da especificidade de cada método, há aquilo a que Perraudeau chama de «educabilidade cognitiva» ${ }^{22}$ e que, apesar de, perante as diversidades, ser impossível estabelecer uma delimitação semântica, podemos sublinhar alguns elementos em torno dos quais quase todos os métodos se juntam: a) Arquitectura conceptual com princípios explicitamente definidos; b) Desenvolvimento das operações intelectuais ou dos processos de aprendizagem; c) Desenvolvimento da capacidade de comunicação pela aplicação de situações de interacção social; d) Desenvolvimento da autonomia do aluno; e) Aumento da capacidade de transferência, privilegiando alguns métodos uma descontextualização disciplinar nas situações propostas; f) Importância dada ao papel do adulto, formador, professor, como ajuda, tutela, mediação.

Assim, após aturada ponderação sobre os aspectos acabados de focar e consciente de que «todos os modelos são redutores e perigosos se transpostos mecanicamente, mas, quando usados como auxiliares, podem constituir-se em elementos de grande utilidade ${ }^{23}$, gizei, para uma turma de História do $12^{\circ}$ ano, o 
seguinte cenário ${ }^{24}$, obedecendo às fases da sintaxe do modelo Resolução de Problemas:

\section{Reconhecimento do Problema (45 m):}

O professor apresenta o problema à turma, escrevendo no quadro a seguinte questão: Sabendo que os regimes totalitários são pouco propensos a descentralizar, como entender que o Concelho de Palmela restaure o seu estatuto concelhio, em Novembro de $1926 ?^{25}$

. Entretanto, pede um voluntário para ler a frase do quadro em voz alta, estratégia aparentemente insignificante, mas com o objectivo concreto de começar a activar a motivação e a capacidade de exploração.

. Seguidamente distribui a cada aluno uma síntese da História do Concelho de Palmela e convida-os a uma leitura silenciosa do texto, pedindo para sublinharem o que acharem pertinente para entender o enunciado do problema.

. Socorrendo-se da estratégia do Questionamento, sob a forma de Pergunta Circular ${ }^{26}$, para obter a participação de todos, tenta focar a atenção no que se pretende saber e certifica-se que todos os alunos entenderam e sabem especificar os dados explícitos do problema.

\section{Análise da situação problemática $(90 \mathrm{~m})$ :}

Nesta fase pretende-se manter a motivação e favorecer a mobilidade mental, usando pontos de ancoragem como a capacidade de escuta, a vigilância e a atenção. Será novamente usada a estratégia do Questionamento, na sua modalidade Socrática, levando os alunos a convocarem os conhecimentos prévios relacionados com esta problemática.

. Inspirando-se no método Ramain ${ }^{27}$ serão propostos exercícios que desconcertam paradoxalmente pela sua simplicidade, usando materiais simples como papel e lápis: associar conceitos como Liberalismo, Democracia, Descentralização, Municipalismo e fazer o mesmo com conceitos opostos.

. Com a ajuda do professor, os alunos chegam à identificação de dados implícitos no problema e que devem ser pesquisados (por exemplo: em que contexto foi extinto o concelho de Palmela e que aspectos relevantes há a assinalar nos 71 anos em que esteve dependente de Setúbal?), dando palpites sobre o modo como devem 
proceder para obter esses dados (Internet/site do Arquivo Municipal, Jornais Locais, testemunhos orais de familiares dos restauradores do concelho, anotação de dados inscritos nas estátuas de vultos concelhios espalhadas pela vila...).

. Utilizar-se-á a Estratégia $635^{28}$ que consiste na escrita por seis participantes de três ideias em cinco minutos. Depois, cada aluno, rotativamente, recebe as folhas dos outros participantes e acrescenta, em cada cinco minutos, mais três novas ideias e assim se pretende estimular a produção de novas ideias.

\section{Delineamento de estratégias de resolução (45 m):}

Os próprios alunos são convidados a desdobrar o problema inicial em vários sub-problemas, colocando hipóteses para a sua resolução, mediante provocação do professor, através de estratégias tendentes a evitar confinar os alunos a uma rotina de repetição ou induzi-los a respostas automáticas.

. O professor, sempre no seu papel de mediador/condutor, socorrerse-á de uma Estratégia de Simulação, neste caso, associada à técnica da História Virtual ou Contrafactual ${ }^{29}$. A partir da pergunta «E se...?» (que à primeira vista convidaria ao adivinhar), os alunos, colocando-se na pele de pequenos historiadores, imaginam hipóteses viáveis em novos contextos (se um acaso invertesse a corrente dos acontecimentos), e simulam respostas prováveis, interiorizando que a ciência não é um conjunto de dados objectivos, mas uma construção/desconstrução/ reconstrução sempre inacabada.

. Decide-se que a melhor estratégia a seguir na fase seguinte será a do Inquérito, conduzida no contexto de Trabalho de Grupo, nas suas três modalidades ${ }^{30}$ : Pesquisa Bibliográfica, Trabalho de Campo e Estratégia Biográfica.

\section{Concretização (Tempo a definir) ${ }^{31}$ :}

Os alunos formam grupos livres e cada grupo estabelece, após negociação, as tarefas a realizar, calendariza-as com rigor, sempre sob coordenação do professor.

- Primeiro será a fase da Pesquisa Bibliográfica, estratégia de procura da informação sobre todos os ângulos já inventariados do problema inicial, abarcando todos os suportes possíveis: áudio, scripto e redes de informação e comunicação como a internet. 
. O Trabalho de Campo será realizado, evidentemente, fora da aula, após a elaboração de um guião escrito onde figure claramente o que se deve fazer, porquê e para quê. Cada grupo recebeu do docente um guião (elaborado a partir da recolha dos resultados das fases anteriores) com Heurísticas e Algorítimos de Resolução de Problema, seleccionando as acções que melhor se ajustam aos respectivos subproblemas.

- A Estratégia Biográfica consiste na utilização de Biografias de vida de pessoas que se destacaram em determinada área ou campo de estudo (neste caso, lutadores pela restauração do Concelho de Palmela através de várias acções cívico-políticas). Através do contacto com essas vidas, os alunos podem compreender melhor o contexto histórico-social e as suas relações o a questão fulcral do problema. É nesta fase que a estratégia da História Virtual desempenha o seu papel.

. Ficou decidido que o produto final (produção de entrevistas históricas e sua dramatização) seria apresentado a toda a comunidade escolar no Anfiteatro da escola, na festa de fim do ano lectivo e, no ano lectivo seguinte, numa das Sociedades Recreativas da terra, no âmbito das comemorações da Restauração do Concelho, para as quais se convidaria familiares dos restauradores.

\section{Análise de processos e de resultados $(90 \mathrm{~m})$ :}

- Após a apresentação do trabalho de campo de cada grupo e do convite à auto-reflexão, num processo de metacognição ${ }^{32}$ provocada pelo professor, tenta-se chegar a uma solução conjunta, não a partir da soma das partes, mas da análise dos resultados das várias pesquisas parciais em torno, afinal, do mesmo problema (embora desdobrado em vários sub-problemas).

. O professor, usando mais uma vez a Estratégia do Questionamento Socrático, convida os alunos a apreciarem se o que obtiveram se encontra dentro do que era esperado e se tem pertinência para a resolução, desafia-os a reverem estratégias e a procurarem possíveis fontes de erro, vendo-o como um meio de aprender. 


\section{CONCLUSÃO}

Esta experiência ajudou a consolidar a convicção de que os modelos, tal como os próprios paradigmas que os inspiram, não se excluem uns aos outros e devem mesmo ser usados todos, desde que sabiamente adaptados a cada contexto concreto, daí a importância da preparação dos professores no sentido de dominarem um imenso repertório para serem capazes de praticar um ensino diferenciado.

A escolha dos modelos deve ter em atenção os objectivos pretendidos e os sujeitos concretos, suas personalidades e anseios. Daqui decorre a necessidade de nunca nos centrarmos apenas num, antes proceder a uma combinação de métodos e técnicas que podem cruzar vários modelos. Até porque, como Hilary Steedman ${ }^{33}$ chamou a atenção, qualquer modalidade de ensino, dentro do sistema de educação formal ${ }^{34}$, pretende desenvolver quatro domínios de competências: resolução de problemas, capacidades de comunicação, conhecimento e compreensão dos mecanismos sociais e capacidade de auto-avaliação e de auto-responsabilização pelo próprio desenvolvimento.

À medida que caminhamos para um ensino centrado em competências e para a transdisciplinaridade, não tenderá a esbater-se a ideia de que há modelos mais adequados para leccionar certas matérias? A grande questão não será antes: que alunos aprendem melhor esta matéria com este modelo ou com aquele?

Mesmo numa aula em que se opta por utilizar métodos mais ligados aos modelos cognitivos, a dimensão afectiva e social está sempre presente. Nunca podemos esquecer que o que está em causa é assegurar uma organização escolar que não seja desequilibradamente apenas voltada para valores científicos e técnicos e investir também nos domínios da construção da personalidade, porque, como diz Mary Catherine Bateson (1994) ${ }^{35}$, «a educação é cada vez menos uma preparação para a vida e cada vez mais parte da vida», caso contrário, corremos o risco de preparar crianças para «a auto-alienação de uma adultez civilizada transformando-as em ratos adormecidos demasiado dóceis» e, parafraseando António José Saraiva, «o antónimo de educação não é instrução, mas sim amestragem. Educar é fazer com 
que cada um se desenvolva em conformidade com a sua natureza. Amestrar é conseguir que o educando se adapte e se submeta a um Levitã a que chamamos Estado ou Igreja ou Planificação, ou Economia próspera ou a outra qualquer abstracção que viva à custa dos homens» ${ }^{36}$.

A nossa experiência comprova que a História, em geral e a História Local, em particular, prestam-se a um tratamento na linha do modelo em estudo e este aspecto torna-se tanto mais importante, quanto sabemos que, num contexto de globalizações, só uma real valorização das culturas locais e regionais pode esbater os seus efeitos nefastos. As mais-valias para os alunos e para toda a comunidade são evidentes e só podemos combater a resistência a este tipo de práticas, apostando na formação de professores e redimensionando a escola para uma autonomia real.

Se é verdade que teria sido possível chegar a esta constatação por outras vias (até pela simples leitura de um texto!), o modelo Resolução de Problemas, pelas suas potencialidades, como o realce para questões geradas pelos próprios alunos e por fomentar o domínio de procedimentos para dar respostas a situações distintas e mutáveis, chama a atenção para a especificidade e contribui para criar o hábito e a atitude de encarar a aprendizagem como um problema para o qual se tem que encontrar e construir as respostas, porque, como diz Sorel ${ }^{37}$, «aprender é pôr em acção actividades mentais e estratégias, combinadas com o conjunto das variáveis de situações consideradas pelo sujeito».

\section{Notas}

${ }^{1}$ Trabalho realizado no ano curricular de um Mestrado em Supervisão Pedagógica (Universidade Aberta Portuguesa), no âmbito da Unidade Curricular Ensinar e Aprender: Teorias e Práticas, leccionada pelas Professoras Doutoras Isolina Oliveira e Ivone Gaspar. ${ }^{2}$ Licenciada em História pela Universidade de Lisboa, com especialização Pós-Graduada em Supervisão Pedagógica pela Universidade Aberta Portuguesa e docente na Escola Secundária de Palmela (Setúbal, Portugal). ocl@netvisao.pt.

${ }^{3}$ Duas Metodologias de Ensino em Educação a Distância Online, Revista «Discursos», ${ }^{\circ}$ 1, pp. 65-75, Dezembro de 2003.

${ }^{4}$ Os dados sobre estas correntes foram obtidos através do estudo fornecido via on-line pelos meus Professores de Mestrado: Maria Ivone Gaspar, Alda Pereira, António Teixeira e Isolina Oliveira, o qual funcionou com texto de referência (2008). 
${ }^{5}$ Wilson Azevedo, num interessante artigo da Revista «Discursos», $\mathrm{n}^{\circ} 1$ (Dezembro de 2003), intitulado Pioneiros da Educação Online: o que eles têm a nos ensinar? (pp. 103110) chama a atenção para a importância de «cometer somente erros novos», caso contrário, insistir nos mesmos erros, seria sinónimo de incapacidade de evoluir.

6 Gaspar et al. (texto de referência).

${ }^{7} \mathrm{O}$ facto de alguns destes nomes também aparecerem ligados a certas dimensões do paradigma cognitivo comprova o carácter flexível e interactivo dos conceitos em estudo. 8 2001: 10.

9 Estes conceitos serão clarificados no ponto 4.

${ }^{10}$ In Grave-Resendes (coord.), 1999: 76-78.

${ }^{11}$ Seguimos o conceito de metodologia de Silva e Pinto (1986: 252): «corpo misto de conhecimentos onde se interligam, para além das técnicas próprias de uma disciplina científica ou apropriáveis por ela, elementos teóricos e epistemológicos subjacentes quer àquelas quer à prática no seu conjunto da investigação». Mais adiante, apresentaremos o conceito de método.

12 Jorge Valadares e Odete Sansão, in Grave-Resendes (coord.), 1999: 81.

13 O conceito basilar da teoria de Vygotsky é o de Zona de Desenvolvimento Próximo, definido como a distância entre o nível de desenvolvimento intelectual que a criança consegue atingir autonomamente e o que ela é capaz de adquirir, se for ajudada.

${ }^{14}$ Gaspar et al. , Texto de referência.

${ }^{15}$ Citado por Perradeau, 2000: 117.

16 Perraudeau, 2000: 15 e 231-232.

17 Grave-Resendes, 1999: 77-78.

${ }^{18}$ Este autor acredita que quando a aprendizagem se baseia numa estrutura, é muito mais duradoura e, para ele, a estrutura de qualquer corpo de conhecimentos é caracterizada de três formas: modo de apresentação (que tem que ser adequado a cada nível etário), economia de apresentação (quanto menos informação, melhor) e poder de apresentação (quanto mais simples, mais o aluno vê as relações). Bruner preza a Aprendizagem pela Descoberta e valoriza os processos indutivos na aquisição dos conceitos.

${ }^{19}$ Gaspar et al. , Texto facultado online.

20 1998: 19.

21 1992, citada por Perraudeau, 2000: 128-132.

22 O autor (2000: 66-86) fala ainda em Estilos Cognitivos de Ensino (relacionados com a postura do docente e apresenta tês categorias, todas em interacção: Estilo Pessoal gestão dos parâmetros individuais; Estilo Relacional - gestão da relação social professor/ alunos; Estilo Didáctico - gestão das escolhas metodológicas) e Estilos Cognitivos de Aprendizagem do Aluno (Acentuação/Igualação; Centração/Eliminação; Impulsividade/ Reflexão; Evocação Visual/Auditiva; Abordagem Dura/Branda; Controlo Interno/Externo; Dependência/Independência, etc.), para os quais indica estratégias adequadas, convocando autores como Ausubel, Bono, Bruner, Kagan, Papert, Witkin e outros.

23 Azevedo e Azevedo, 1998: 19.

24 Segundo Inácia Santana (Grave-Resendes, 1999: 118), «o cenário consiste na organização do material pedagógico em áreas de trabalho, de maneira a que tudo o que se relaciona com cada uma das áreas esteja ao alcance de todos num determinado espaço, devidamente identificado».

25 Convém lembrar que, nesta altura do seu percurso, os alunos já sabem que Portugal vivia em Ditadura desde 28 de Maio de 1926.

26 Note-se que o arranjo do espaço físico também é muito importante e esta estratégia implica que previamente se coloque as mesas em círculo, daí a sua designação.

${ }^{27}$ Referido por Perraudeau, 2000: 177-178. 
28 Vieira e Vieira, 2005: 26.

29 Criada nos anos 90, em Inglaterra, por Fergusson e que dá os seus primeiros passos no nosso país.

${ }^{30}$ Vieira e Vieira, 2005: 37.

31 Em função do ritmo de cada grupo (atendendo, particularmente, aos ritmos individuais) e do modo como decorrer o trabalho extra-aula.

32 Conceito que é definido por Flavell (citado por Perraudeau, 2000: 123) como «o conhecimento das operações que intervêm numa actividade cognitiva», por Britt-Mari Barth (citada por Altet, 1999: 50-51), como «um mecanismo de transferência de conhecimentos e atitudes... através da mediação cognitiva» e por Sprinthall (1994: 112) como a «capacidade do adolescente para pensar sobre o seu próprio pensamento e sobre o pensamento dos outros».

33 Citada pela Professora Ivone Gaspar no citado artigo da Revista Discursos (p. 67).

34 Carlos Alberto Silvestre (2000: 54-55) apresenta um quadro completo das diferenças entre a EF (Educação Formal), a ENF (Educação Não Formal) e a EI (Educação Informal).

35 Citada por Antunes, 2001: 225-226.

${ }^{36}$ António José Saraiva (1985) citado por Sousa, 2003: 44.

37 In Perradeau, 2000: 231.

\section{Referências}

ALTET, Marguerite. As Pedagogias da Aprendizagem. Lisboa: Instituto Piaget, 1999.

ANTUNES, Conceição. Teoria e Prática Pedagógica. Lisboa: Instituto Piaget, 2001.

ARENDS, Richard I. Aprender a Ensinar. Lisboa: McGraw-Hill, 1997.

AZEVEDO, Carlos e AZEVEDO, Ana. Metodologia Científica, Contributos práticos para a elaboração de Trabalhos Académicos. Porto: Porto Editora, 1998.

BERTRAND, Yves. Teorias Contemporâneas da Educação. Lisboa: Instituto Piaget, 2001.

DELORS, Jacques (org.). Educação, um Tesouro a Descobrir. Edições ASA, Porto, 2005.

GRAVE-RESENDES, Lídia (coord.). Ensinar diferente para a diferença no Aprender. Pedagogia Diferenciada: da Exclusão à Inclusão Pedagógica. Lisboa: Universidade Aberta, 1999. 
GASPAR, Ivone, PEREIRA, Alda, TEIXEIRA, António e OLIVEIRA, Isolina. O Modelo na Relação do Ensino com a Aprendizagem. Texto facultado online pelos autores, 2008.

JOYCE, Bruce e WEIL, Marsha. Modelos de Enseñanza. Madrid: Ediciones Anaya, 1985.

PERRAUDEAU, Michel. Os Métodos Cognitivos em Educação, Aprender de outra forma na escola. Lisboa: Instituto Piaget, 2000.

POURTOIS, Jean-Pierre e DESMET, Huguette. A Educação Pós-Moderna. Lisboa: Instituto Piaget, 1999.

SILVA, Augusto Santos e PINTO, José Madureira. Metodologia das Ciências Sociais. Porto: Edições Afrontamento, 1986.

SILVESTRE, Carlos Alberto. Educação/Formação de Adultos Como Dimensão Dinamizadora do Sistema Educativo/Formativo. Lisboa: Instituto Piaget, 2000.

SOUSA, Alberto. Educação pela Arte. Lisboa: Instituto Piaget, 2003.

SPRINTHALL, Norman e SPRINTHALL, Richard C.. Psicologia Educacional. Lisboa: McGraw-Hill, 1993.

VIEIRA, Rui Marques e VIEIRA, Celina. Estratégias de Ensino/Aprendizagem. Lisboa: Instituto Piaget, 2005.

\section{Abstract:}

\section{Cognitive Models of teaching and Pedagogical Practices - Planning a History Class in accordance with Problem Solving model.}

With this paper I intend to research the understanding of the Cognitive Paradigm, taking as a starting point its relation with one of the models it inspired - the Problem Solving model, applied to a History lesson. In the first part, I'll begin by clarifying the underlying concepts, paradigm and 
model bringing to light their dialectic relations. Then I'll describe the cognitive paradigm, its foundations, main vectors and defining aspects. After presenting an overview of the cognitive teaching models, in which I'll make reference to the conceptual constants that structure their practice, I will focus on the Problem Solving model and describe its sintax. In a second part I'll attempt to apply the model in question to a History' lesson scenery of a secondary school, centered on a local History issue.

Keywords:Models of teaching. Cognitive Models. Problem Solving model.

Recebido em agosto de 2009.

Aceito em novembro de 2009. 